\title{
Correction: Dose and type of crystalloid fluid therapy in adult hospitalized patients
}

Annemieke Smorenberg, Can Ince and A B Johan Groeneveld*

After the publication of this work [1] it was brought to our attention that there was an error in Table two (Table 1 here) of the article, in which the table columns were misaligned. The correct version of the table is included here:

Table 1 Composition of bodyl fluids (in $\mathrm{mmol} / \mathrm{L}$ )

\begin{tabular}{|c|c|c|c|c|c|c|c|c|c|c|}
\hline & $\mathrm{Na}^{+}$ & $\mathrm{K}^{+}$ & $\mathrm{Ca}^{2+}$ & $\mathrm{Mg}^{2+}$ & $\mathrm{Cl}^{-}$ & $\mathrm{HCO}_{3}^{-}$ & $\mathrm{HPO}_{4}^{-}$ & $\mathrm{HSO}_{4}^{-}$ & Organic acid & Protein \\
\hline Plasma & 142 & 4 & 5 & 2 & 101 & 27 & 2 & 1 & 6 & 16 \\
\hline \multicolumn{11}{|c|}{ Plasma water } \\
\hline & 153 & 4.3 & 5.4 & 2.2 & 109 & 29 & 2.2 & 1 & 6.5 & 17 \\
\hline \multicolumn{11}{|c|}{ Interstitial water } \\
\hline & 139 & 4 & 5 & 2 & 114 & 31 & 2 & 1 & 7 & 1 \\
\hline \multicolumn{11}{|c|}{ Intracellular water } \\
\hline & 10 & 160 & 2 & 26 & 3 & 10 & 100 & 20 & & 65 \\
\hline
\end{tabular}

Received: 13 May 2014 Accepted: 14 May 2014

Published: 23 May 2014

\section{Reference}

1. Smorenberg A, Ince C, Groeneveld ABJ: Dose and type of crystalloid fluid therapy in adult hospitalized patients. Perioper Med 2013, 2:17.

\section{Submit your next manuscript to BioMed Central} and take full advantage of:

- Convenient online submission

- Thorough peer review

- No space constraints or color figure charges

- Immediate publication on acceptance

- Inclusion in PubMed, CAS, Scopus and Google Scholar

- Research which is freely available for redistribution

\footnotetext{
* Correspondence: a.b.j.groeneveld@erasmusmc.nl

Department of Intensive Care, Erasmus Medical Centre, 's Gravendijkwal 230,

3015 CE Rotterdam, The Netherlands
}

\section{() Biomed Central}

